\title{
COPIM
}

\section{Exploring Models for Community Governance}

\section{Sam Moore ${ }^{1}$}

${ }^{1}$ Centre for Postdigital Cultures, Coventry University

Published on: May 06, 2021

DOI: $10.21428 / 785 a 6451.0304 a 2 a 8$

License: Creative Commons Attribution 4.0 International License (CC-BY 4.0). 


\section{Introduction}

Community governance is rapidly becoming an important topic in scholarly communication. As control of academic publishing has been largely ceded to private firms within the market, many researchers are now arguing for new kinds of governance by the diverse communities that hold a stake in the academic publishing industry (Fyfe et al.,2017; Moore,2020). This will allow the workflows and infrastructures for publishing to be accountable to a broader range of stakeholders, such as authors, librarians, early-career researchers, the broader public, and of course, publishers.

This report has been created as a research output to support the COPIM project. COPIM (Community-led Open Publication Infrastructures for Monographs) is an international partnership of researchers, universities, librarians, open access book publishers and infrastructure providers. Funded by the Research England Development ( RED) Fund and Arcadia - a charitable fund of Lisbet Rausing and Peter Baldwin - COPIM is building community-owned, open systems and infrastructures to enable OA book publishing to flourish.

As part of seven connected work packages, COPIM will work on 1) integrated capacitybuilding amongst presses; 2) access to and development of consortial, institutional, and other funding channels; 3) development and piloting of appropriate business models; 4) cost reductions achieved by economies of scale; 5) mutually supportive governance models; 6) integration into library, repository, and digital learning environments; 7) the re-use of and experimentation with OA books; 8) the effective and robust archiving of OA content; and 9) knowledge transfer to stakeholders through various pilots.

Work package 4 of the COPIM project is exploring community governance with a view to designing the policies and procedures for community oversight of the infrastructures and models that the overall project is developing. Our aim is to create durable organisational structures for the coordination, governance, and administrative support of the project's community-owned infrastructure. This includes developing new avenues of outreach, communication, and partnership with diverse stakeholders in open research with a shared interest in this infrastructure, creating genuine community involvement and collective control. In conducting this research, which is reflected in this report as well as in our forthcoming reports, we hope both to learn from the governance models that our colleagues in scholarly communication are 
utilising thus far and to look to the future of community governance for academic publishing.

This report presents initial work on the various models that already exist for community governance and discusses their pros and cons for COPIM's open access monograph infrastructures, particularly its consortial funding programme. It does this through 1) a landscape study of forms of governance within scholarly communication and 2) an exploratory study of the theoretical literature on alternative forms of governance appropriate for community-led organisations

\section{Methodology, structure, and notes on governance}

This report presents desk research undertaken during the latter half of 2020, based mostly on information collected from project websites, case studies, and the academic literature on community governance. This means that to be included in the report, organisations will have had to make their governance models publicly known somehow. The author does not feel this approach is too controversial for studying community governance, particularly as there is an expectation that 'open' organisations should present transparent governance where possible.

The report also draws on insights gathered from a workshop we conducted in collaboration with UCSB Library for the COPIM project focused on community governance which brought together governance experts, key stakeholders in OA book publishing, and representatives from allied large community-led projects, to collaboratively explore what the governance procedures of COPIM's open publication ecosystem for monographs should look like and to begin thinking about developing models to sustain the governance of the infrastructure as a community-based OA service organization. These reports are dedicated to discussion of the meaning_of community and the features of good governance.

In our initial work defining community governance, we identified a number of features and considerations that good governance necessitates [ㅍ]. We define these as

1. the scale or scope of the organisation,

2 . the formality of the governance system required, and

3. the extent to which the governance relates to the mission of the project.

All of these considerations are important in shaping the most appropriate model for a project (see section below on various commons frameworks for more) and define the norms, rules, structures, and principles that determine how a project is governed. This 
is to say that our conclusion was that good governance is situated, i.e., it is highly specific to the resource and community in question. For the purposes of this report, we are interested in governing open-source, digital infrastructures, and financial models for the long-term sustainability of open access book publishing. The COPIM project is decentralised, distributed across a variety of geographical contexts (albeit predominantly focusing on the US, UK, and EU as that is where the project partners are situated), and favours horizontal modes of cooperation that foreground nonhierarchical structures, cooperation, and coordination between groups of pre-defined stakeholders [4]. These stakeholders are either active participants of the project (members of COPIM, library funders, etc.) or they may be representatives of stakeholder groups relied upon for accountability purposes (authors, early-career researchers, etc.).

Freeman (1984). defines stakeholders as 'any group or individual who can affect or is affected by the achievements of the organization's objectives'. It is vital for organisations to account for the stakeholders that make up the community, not least because of the vagueness of the term community. During the COPIM governance workshop, Chris Land spoke of the 'material and economic interconnections between people' that the term 'stakeholders' may reveal. Despite its corporate associations, 'stakeholders' may hold more radical potential for its specificity of purpose, Land argues. Community, on the other hand, has positive associations but does not imply difference within the community and so can be somewhat simplistic. For a robust interrogation of models for community governance, it is also important to understand the different communities of stakeholders that overlap within the organisation.

Similarly, it is important to consider what governance means in the context of community governance. Governance is not the same as management and therefore does not refer to the day-to-day running of an organisation. Instead, governance is more strategic and refers to the structures and values that shape an organisation's work, including the accountability and oversight of structures and values. As we will see within the report, governance comprises a number of different elements such as organisational structure, mission statements, principles, values, voting rights and bylaws. It is the job of good governance to define these elements and to ensure they are correctly applied and continually up-to-date. As Raym Crow writes on scholarly communication, community governance is usually inclusive or cooperative [ㅁ]. For inclusive governance, overall control rests with a central organisation but is made accountable to a broader community through various structures such as voting, steering boards and bylaws (each explored below). For cooperative governance 
(explored in part 2 of the report) ownership and accountability rests with all the contributors to the organisation itself.

\section{Structure of the Report}

The report presents a study on scholarly communication governance models, i.e., those already in operation within the publishing community, and a more theoretical exploration of community governance more generally. The first section of the report looks at the variety of models that community-led organisations employ within the scholarly communication space, while the second section explores the theory behind more general approaches to commons, cooperative and community-led forms of governance, aiming to assess their strengths and weaknesses for organisations like COPIM.

\section{Part 1: Overview of governance models used in scholarly communication}

The Association of College \& Research Libraries defines scholarly communication as the 'system through which research and other scholarly writings are created, evaluated for quality, disseminated to the scholarly community, and preserved for future use' [7]. Scholarly communication organisations comprise publishers, academic libraries, repositories, social networks, discovery services, persistent identifier maintainers, and a variety of other bodies involved in knowledge production and dissemination, including non-profits, community-led organisations and for-profit companies. As publishing is a heavily marketised activity, one might assume that formalised community governance structures are not needed because customers are buying and selling an organisation's products - so-called 'voting with their feet' under the assumption that if they are not happy with a product or service they can just pay for a different one. Yet it is precisely the lack of accountability associated with market-centric forms of organisation that COPIM looks to avoid through a focus on multi-stakeholder, community-led forms of governance. Market-centric forms of governance may emphasise individuation and competition rather than equitable forms of stakeholder accountability. In academic publishing, for example, this lack of stakeholder accountability is on display in the exorbitantly high prices of text books sold by publishers back to the academic instructors who write them [].

The next section provides examples of some of the governance structures being used within scholarly communication, along with considerations on values, principles, bylaws and other relevant issues. Through analysis of a number of examples from a 
range of scholarly communication organisations, the section aims to illustrate some of the advantages and disadvantages of different approaches to governance in scholarly communication.

\section{Advisory board / steering committee}

From startups to not-for-profits, one of the most common structures used within community governance in scholarly communication is based on the advisory board or steering committee. Usually composed of a small number of experts and senior figures from allied stakeholder organisations, advisory boards are convened to provide input on decision-making and strategic direction, either at the individual, ad hoc level, or through regular board meetings. This means that advisory boards are often external to the project, or at least not composed by active participants within the project itself, and so are called upon for direction and accountability.

In scholarly communication, there are numerous examples of advisory boards and steering committees. For example, the media studies preprint archive MediArXiv is governed by a steering board to contribute to moderation and policymaking. Members of the steering board are all active academics working in media studies who set direction for the repository and determine whether content is acceptable to be uploaded. Without further rules or bylaws dictating how the board should operate, as is often the case with community-based organisations, advisory boards are reactive to the requests from an organisation's founders. Unless stipulated otherwise, they are not in possession of actual power but only participate in an advisory capacity. In these cases, accountability rests with the founders, directors or managers of the project calling upon the advisory board to provide advice when needed, which means that a system of community governance that rests solely with an advisory board may be more appropriate for small, nascent or informal projects.

Yet coupled with other governance measures such as bylaws, advisory boards and steering committees can form a more structured, proactive form of governance by a stakeholder community. For example, SPARC is governed by a committee that 'represents the membership and provides rapid programmatic decision-making support'. The SPARC board is composed of representatives elected by full (paying) members, while other categories of membership are not entitled to elect board members. Elected board members vote on issues presented to the board by SPARC, while SPARC also appoints members to the board who do not receive a vote on issues. Governance of SPARC is therefore weighted towards those who financially sustain the organisation, although the organisation does state that their governance model is 
broadly representative of all stakeholders due to its representation of different consortia on its board.

Though SPARC's rules and bylaws are not publicly available, its approach to governance is intended to 'ensure agility and provide a level of participatory governance that will not impair its responsiveness to a fast-changing marketplace'. The emphasis on agility is perhaps framed as in tension with democratic community oversight, meaning that organisational founders are often keen to maintain the ability to make quick decisions without continual need to defer to board members. This is to say that although SPARC's advisory board + voting model is more structured than MediArXiv's, the community representation for its 240 plus members is concentrated within its ten elected advisory board members. It provides oversight but is ultimately still quite centralised as a model of community governance. This agility might be beneficial for smaller, leaner organisations, but it may not work for multi-stakeholder projects like COPIM that ideologically demand a more distributed approach with multiple centres of power.

\section{Multi-board governance structures}

Alongside the single advisory board structures explored so far, it is worth also considering more complex distributed models involving multiple boards with differing areas and levels of responsibility. These structures allow oversight of discrete areas within a community-driven organisation and facilitate different interactions between them, allowing distributed decision-making that may filter into a more centralised board structure. The following is an overview of these models with key considerations about how each model may work for COPIM or similar multi-stakeholder communitydriven projects or organisations.

\section{Open Library of Humanities}

Multi-board structures can be similarly ad hoc or reactive as the single board structures described above, meaning that they may not have specific delegated powers but are simply called upon as and when they are required. For example, the $\underline{\text { Open }}$ Library of Humanities operates an academic advisory board and a board of library member stakeholders, the former being appointed by the organisation's founders and the latter being a responsibility of the libraries that support OLH financially. Academic advisors are called upon to 'advise the CEOs when requested on any matter pertaining to academic rigour', while library members are tasked on a quarterly basis with voting on journals to admit to the platform. Unlike other governance structures we will 
explore, voting rights are not weighted by organisation size here. Instead, each member receives one vote per OLH subscription paid. An important question in community governance is therefore how to weight community contributions: by organisation size, financial contribution, or simply according to one member, one vote? These considerations relate not just to governance but also the practicalities of the kind of financial model that supports the organisation (in COPIM's case, how the consortial funding scheme will operate, for example).

\section{Humanities Commons}

Humanities Commons operates a multi-board structure with two sub-groups (focused on technical and user requirements, respectively) feeding into a main governing Participating_Organization Council. Currently in development, the Council will be elected by participant organisations. The Council's remit is to provide input on:

[...] strategic decisions and fiscal operations, including, participation policies, terms, and fees (which will take into account the type and size of the participating organization); development priorities; resource allocations; and how to build the Commons community within and across societies and institutions.

The council also oversees the technical and user advisory groups. The technical advisory group set priorities for technical developments and the user advisory group will represent the needs and interests of scholars on the platform, setting priorities for 'usability, features and functionality, and investment priorities'.

With representation from supporting member organisations, and specific boards for different themes setting priorities, the Humanities Commons governance model moves closer towards a form of governance that is democratically shared between all participants. Yet control of the bylaws ultimately rests with Michigan State University, where the project is based, and they reserve the 'sole and exclusive authority to determine, in its discretion, whether a proposed amendment should be adopted' (see section below on bylaws). There is thus a tendency for some organisations to centralise power when a project or service is based at a particular institution (MSU in this case) and this can override democratic community governance. In our workshop on community governance, Kathleen Fitzpatrick described her experience in running Humanities Commons and the importance of considering 'the distinctions between projects/organisations/entities for which the governing body has certain legal and fiduciary responsibilities and the authority and organisations for which that governance body would be advisory'. In assuming the ultimate responsibility for the 
project, the parent organisation of a community-led project can therefore impact the governance model quite significantly.

\section{arXiv}

Similar to Humanities Commons, the physics preprint repository arXiv has a multiboard structure that feeds into a centralised Leadership and Operations team (see Figure 1). Alongside a representative board composed of members that financially contribute, and a technology advisory group, arXiv is also governed by a scientific advisory board and an administrative body based at Cornell University, its hosting organisation. The scientific advisory board is responsible for oversight of the intellectual content on the repository; it does this through consensus voting in order to recommend a course of action to the leadership team. Like the Humanities Commons model, the administrative body is made up of staff from its parent institution and the final say in any decision rests with them. Boards contain voted members that are either elected or fee-paying stakeholders, along with non-voting member experts that participate to build consensus.

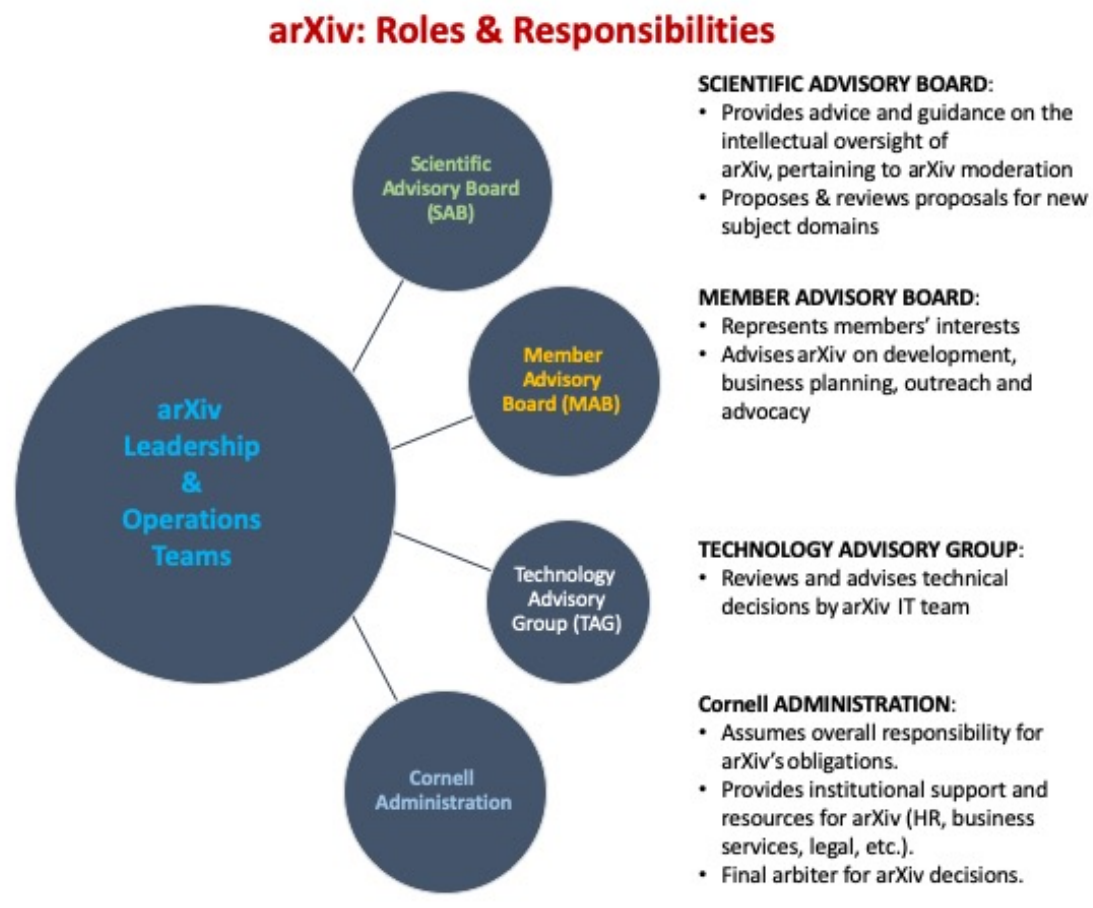

Figure 1

ArXiv governance structure, reproduced under CC BY.

One interesting aspect of the arXiv governance structure is how members contribute based on their usage of arXiv over a three-year period. arXiv specifically seeks out universities and consortia with the highest number of downloads and asks them to 
contribute to the upkeep of the service. Organisations with fewer downloads contribute less, although arXiv is a high-energy physics repository and so the heaviest users are in wealthy institutions. Putting aside the difficulties of accurately understanding which institutions download the most papers, this model is weighted towards the demand rather than the supply side of the organisation and so assumes that those who download the most should pay more. Governance is therefore weighted in favour of those who access papers over those who write and publish them, but also the burden of financial cost falls to the heaviest users. For COPIM, difficult decisions will need to me made around how to include the consumers of monographs in our governance mechanisms. Many less research-intensive institutions are unable to pay for the upkeep of open access publishing even though they stand to benefit the most from free access to academic books.

\section{OPERAS}

OPERAS is a multi-member organisation set up to create and maintain 'research infrastructure supporting open scholarly communication in the social sciences and humanities (SSH) in the European Research Area'. Similar to arXiv and Humanities Commons, the OPERAS organisation maintains a multi-board structure for its governance composed of a General Assembly of member organisations, an executive assembly of members that commit more than others to the development of OPERAS and a scientific committee of experts in humanities and social science publishing. In addition, unlike the organisations studied so far, OPERAS hosts an 'Assembly of the Commons', which is a larger body of representatives from special interest groups and 'ordinary members' in the broader OPERAS community. The Assembly of the Commons is a way for the broader community and smaller interest groups to provide recommendations and advice to the executive assembly.

The OPERAS model is interesting for governing large organisations hierarchically with stakeholders of differing levels of interest or responsibility. Members with more responsibility are given more power to set the OPERAS strategy, while small interest groups can interact on a more informal basis but while still filtering their input upwards to the main organisation. For additional community oversight, the scientific advisory board is composed of independent members of the research community with a regular advisory role. $\underline{1}$

COPIM may not currently be large enough to fully exploit the benefits of this structure, although many of the elements within OPERAS governance structure could be tailored for smaller multi-stakeholder organisations, particularly for those with special interest 
groups. OPERAS is however still quite hierarchical in its structure, which is not desirable for organisations looking for horizontality, and requires a great deal of coordination from central project staff to make it run smoothly.

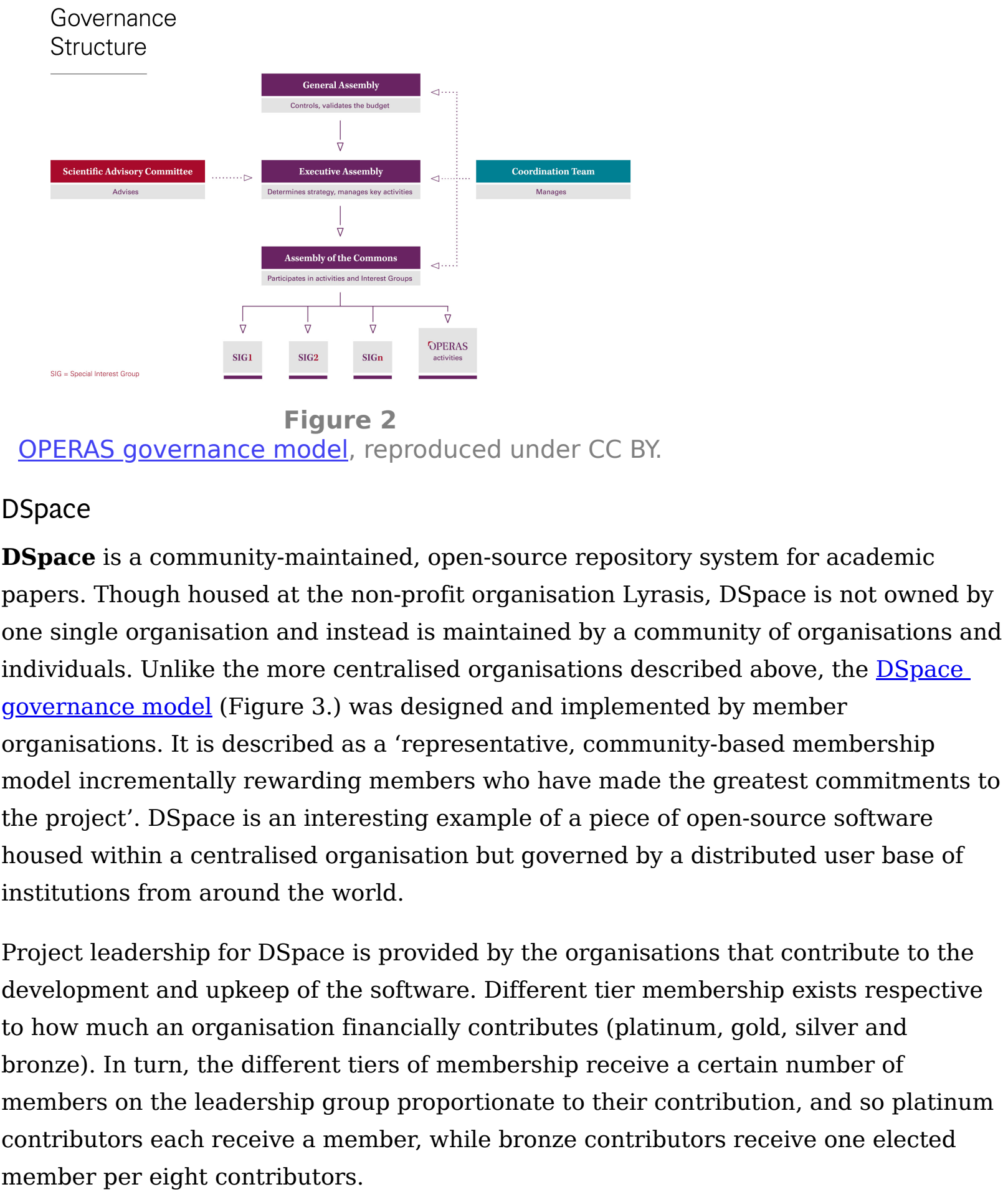




\section{DSpace Governance Model}

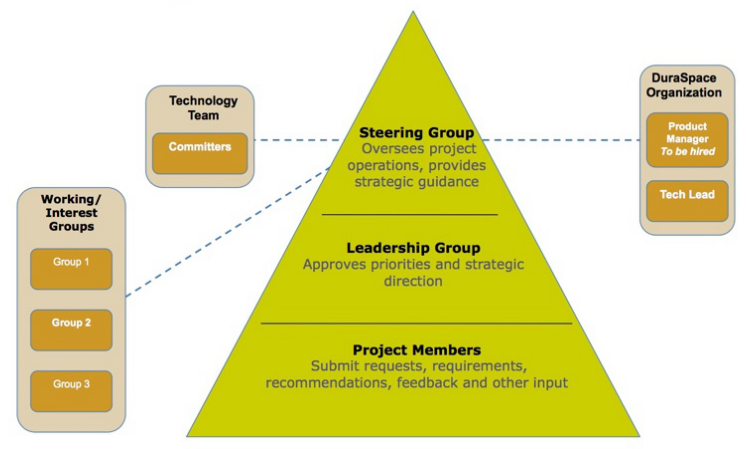

Figure 3

DSpace governance structure (reproduced under CC BY)

Between these two boards, strategic priorities and budgets are set and implemented. These boards also receive recommendations from the broader user community of project members. Much like other governance structures, DSpace hosts boards of special interest groups and a technical advisory committee.

The DSpace model is successful because it gives power to those with an interest in developing the repository system: it also does this through a variety of user forums and other community-maintained sites of interaction. The greater an organisation's contribution to its upkeep, the greater the representation they have on the board that designs how the software is improved. Although this system of governance is successful for keeping organisations involved in software development, it is also weighted towards organisations that can pay more. Less wealthy institutions may have just as much of a stake in the software - not least because it is open source and free to use - but their needs will not be proportionately represented. There is thus a tension between involving high-paying members and ensuring that lower or non-paying members still have a voice.

\section{OASPA Switchboard}

Taking a different approach to the multi-board structure, the recently-launched OASPA Switchboard maintains a membership of smaller open access publishers who collaborate on a variety of different topics relating to their businesses. Unlike the organisations studied so far, the switchboard is not governing an infrastructure per se, but is instead an intermediary between funders, institutions and publishers that reduces the burden of numerous similar interactions between different parties (i.e., libraries dealing with ten different publishers for one service). It is designed with the 
main purpose of sharing resources (financial and informational) between independent organisations that may otherwise be competing, and so it is a structure that could work potentially in some form for consortial funding models in which funds are distributed between numerous presses. Itself governed by a steering committee, the switchboard is an example of how independent organisations may work together to reduce bureaucracy for libraries looking to support open access. Rather than having multiple advisory boards for different discrete areas of a consortium, the switchboard is formed of one member per publisher who represents all areas of the organisation. This is in addition to a centralised payment system for open access charges that can redistribute funds from libraries to publisher members.

With such intermediary governance organisations, it is important to define in advance who is allowed to participate and according to what conditions. Are for-profit actors allowed to participate? How are funds redistributed and who pays for the upkeep of the organisation? For COPIM, many of these issues will be determined by how the initial organisation will be set up. The Switchboard is an independent organisation and so has a degree of autonomy that is different to other centralised organisations. They also require employees who can manage interactions between the various stakeholders with whom the Switchboard interacts. This adds a degree of complexity when one or two employees are being paid by a mixture of competing organisations.

Nevertheless, COPIM is founded on the basis that open access monographs can be created collaboratively rather than by publishers in competition with one another and so such an intermediary structure may be entirely appropriate for illustrating this collaborative approach. New members could join - according to conditions set by the founders - and would then share ownership of the organisation. A similar board could also operate for the library community, although this is not part of the OASPA switchboard itself. Importantly, as with all of the organisational structures analysed so far, the bylaws, principles and values of the organisation are vital for its success, as the next section explores.

\section{Bylaws, principles, and values}

In addition to the board structures that make up a community-governance organisation described above, it is important to consider the rules and norms that govern a project. Broadly speaking, bylaws reflect the rules that govern a project, while mission statements, principles and values reflect the norms that govern an organisation's culture. Codes of conduct are also important in the context of rules and norms (e.g.,

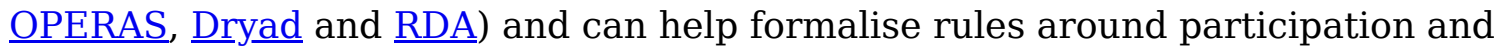


methods for resolving disagreement. It is worth exploring the different approaches to these elements within community-governed organisations, although it is not within the scope of the report to assess the different bylaws themselves, $\underline{2}$ only to understand their method of creation and maintenance.

Most of the organisations mentioned so far have bylaws that tend to be set by project leadership and amended through various voting systems. Bylaws dictate the rules for voting and the formal interactions that take place within the organisation, including how these rules can be changed and how they relate to the organistion's mission. The Research Data Alliance - a multi-stakeholder organisation advocating for open and reusable data - lists the main functions of bylaws as governing the organisation's function, rules around membership, joining, leaving, duration, rights and responsibilities. RDA does this through a document explaining the model in detail, which was drafted by central leadership and approved by voting members. In addition, RDA maintains a code of conduct and a set of operating principles that is shared within a versioned, transparent document. Its guiding_principles are listed as: openness, consensus, inclusive, harmonisation, community-driven, non-profit and technologyneutral. Each principle is accompanied by an actionable statement such as 'RDA does not promote, endorse, or sell commercial products, technologies, or services and the development of open and re-usable recommendations and outputs within the RDA is mandatory'. Members must subscribe to these principles in order to join the organisation (although, from the documentation consulted, it is unclear how the principles are enacted in practice).

Another example of principle-enacted governance is the Ubiquity_Press customer charter, which legally enshrines actionable principles to which the publisher must conform ('open access', 'open source' and 'unbundled products'). This is in addition to an advisory board composed of customers that makes legally-binding recommendations on the publisher's strategy. Similarly, Crossref looks to external principles to govern its efforts, having signed the Principles of Open Infrastructure in 2020. These principles are intended to orient their work towards open infrastructure, taking an appreciation of sustainability, governance, and insurance. Both Crossref and Ubiquity Press illustrate the power of externally-imposed principles within an organisation's work, highlighting how governance does not necessarily need to come from within the organisation itself.

Many other organisations (e.g., ORCiD, AmeliCA) also foreground the values that guide their organisation, usually those that are chosen by or representative of the 
community they serve. For example, alongside a series of actionable principles, ORCiD lists the following values statement:

ORCID is an integral part of the wider digital infrastructure needed for researchers to share information on a global scale. Our work is open, transparent, and non-proprietary. We are guided by the principles of privacy and researcher control and the vision of identifier-enabled research information infrastructure. We make decisions collaboratively, involving our staff, Board, those who support our mission, and the researchers and community that are the purpose of our work.

Listing an organisation's principles, values and mission is key for multi-stakeholder alignment, especially if accompanied by a charter that all stakeholders must agree to in order to participate. In addition, values must not be underestimated in nurturing the culture or norms within an organisation. Yet the vagueness of values also makes it harder to assess whether an organisation is living up to its values, especially when unaccompanied by actionable statements of principle.

In an important piece of work, the Next Generation Library Publishing project appeals to scholarly communication providers to define their values and principles in terms of measurable actions. Living Our Values and Principles: Exploring Assessment Strategies for the Scholarly Communication Field by Skinner and Wipperman explores the misalignment between the values of higher education and profit-driven service providers, making recommendations for how organisations might be able to articulate their own values and measure their work in relation to them. Through an exploration different values within scholarly communication organisations, the authors foreground the following values that are common within the non-profit scholarly communication space: Representation in Governance and Control; Sustainability, Succession Planning and Sunsetting; Equity, Diversity, and Inclusion; Transparency; Openness; Interoperability; Reproducibility / Reusability; and "Public Good" [ㅁ]. Based on these values, Skinner and Lippincott propose a checklist for organisations to assess their commitment to their own values [10]. This is perhaps a helpful starting point for organisations looking to devise their own values statements, although the authors do not provide a method for organisations to do so.

From looking at different approaches to values, we want to come back to the argument that we made at the beginning of this report that good governance is situated. Values emerge out of the particular context and situation at hand, while good governance can be designed to reflect those values and nurture the kinds of cultures that an 
organisation desires. This does not mean that it is easy for an organisation to decide its own values, and no doubt many organisations are founded without explicit values statements, but rather that putting in the work of deciding or elucidating values can help shape the normative interactions with an organisation - the ways that diverse groups of stakeholders relate to one another. Yet the work of values is also related to an organisation's structure: it requires a certain deliberative process and democratic approach so that the 'community' can decide its values. We may not all agree on what values are important to us, but democratic structures may be in place for when we disagree.

By way of concluding this section, it is clear that community governance within scholarly communication organisations and projects is dictated predominantly by the differing interactions between advisory boards (representing members, stakeholders, geographies and areas of expertise), values/principles, mission statements, and bylaws. Community governance in scholarly communication mainly represents a kind of inclusive governance - as described above by Raym Crow - rather than anything fully devolved to a community in the form of cooperativism whereby all participants have equal ownership. This means that, for better or worse, common governance structures in scholarly communication are still quite centralised in that the organisational leadership itself often seeks to dictate the terms for community inclusion and accountability, rather than designing governance structures that devolve power to it. This is also reflected in the fact that the majority of organisations studied here have a centralised organisation that carries the ultimate risk associated with the project. For equitable governance, this situation leads to a continual negotiation between centralised control and devolving powers for key issues to certain stakeholders.

For organisations that desire fully horizontal community control, it is important to understand that there is a balance to be struck between the idealism of community rule and the pragmatism of running an organisation. For COPIM, this will mean defining the activities that need to be governed and the actors who can participate in this governance, in addition to the values, mission and principles that define the organisation's culture. From here, adequate structures and bylaws can be designed to implement this vision. Part 2 of this report covers models from beyond scholarly communication to see what can be learned from other forms of inclusive and cooperative governance outside of the publishing ecosystem. 


\section{Part 2: Community governance outside scholarly communication}

Having outlined the main governance models and considerations within scholarly communication organisations, this report now turns to models outside the scholarly communication ecosystem towards community-led project governance more generally. This section looks at the theory behind community governance, introducing frameworks relating to cooperativism, the commons, and so-called community rule. In doing this, part 2 seeks to provide a robust basis to help COPIM understand what kind of governance system it needs by allowing the community to ask itself the right questions about what kind of organisation it hopes to be.

\section{Community Rule}

Open-source software and free culture have a difficult history with formalised community governance. As Christina Dunbar-Hester's book on open-source software communities shows, many participants of open cultures believe that rules and structures are not needed for their work because they may simply get in the way [11]. Furthermore, as Nathanial Tkacz shows through his work on Wikipedia, where rules are applied in open communities they are often done so as a form of 'ad-hocracy' whereby rules are not implemented according to a systematic or democratic way (Tkacz,_2014, Chapter 3). Indeed, the two traditionally competing models for opensource development, the 'cathedral' and the 'bazaar' models, eschew any formal commitment to governance. For the cathedral approach, associated with the Free Software movement, software is best developed and controlled by a 'benevolent dictator' and shared widely only when the creator thinks it is ready. On the other hand, the bazaar method, associated with the open Source Initiative, is a free for-all-method conducted in the open by anyone who wants to participate, although in practice it is just as open to co-option by a benevolent dictator (Tkacz, 2014, Chapter 1). This is not to say that community governance is not a feature of open cultures, but rather that it was not traditionally integral to the movements and often considered an afterthought.

The lack of governance, or what he terms the 'implicit feudalism' in online communities, has led the activist Nathan Schneider to devise a series of templates for different ways communities can govern their work [13]. On the About page of the CommunityRule project he writes:

Too many of our communities adopt default governance practices that rely on the unchecked authority of founders, admins, or moderators, lacking even basic features of small-scale democracy. The purpose of CommunityRule is to help 
communities establish appropriate norms for decision-making, stewardship, and culture.

The openly-licensed templates are built around particular governance structures and models that are supplemented by community rules intended to be foundational to the organisation's activities. The templates are suggestions that communities may adopt, not actual real-world examples of governance-in-practice. It is therefore worth exploring these templates fully because they represent one of the few examples of such practical work in the open space.

Much like many of the models explored in the previous section on scholarly communication governance, the community rule models include those with centralised or ad hoc distribution of power. For example, 'benevolent dictatorships' and 'doocracies' are good for getting things done without formal decision-making processes. Benevolent dictatorships centralise power with a small number of people, while doocracies, allow any person to choose a role for themselves on the project and to contribute accordingly, or: "Those who step forward to do a given task can decide how it should be done.' For COPIM, neither of these approaches represent well-considered community accountability and we do not feel it is necessary to discuss them here. Community accountability is not a free-for-all, as in the case of a do-ocracy, nor can it be centralised to one person, benevolent or otherwise, running the whole operation.

Looking to more democratic models for community governance where power is shared between different stakeholders, the CommunityRule project suggests a number of models that could be appropriate for a community-led organisation like COPIM, described in the following sections:

\section{Circles}

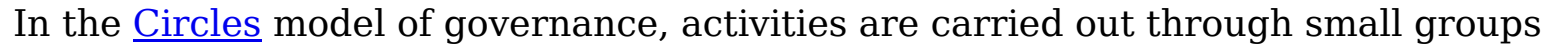
(called circles) that have ultimate control of areas that relate to their particular domain. One representative from each circle sits in a council to determine the scope of each circle and to coordinate on matters between the broader organisation. The council works by unanimous consensus in order to not exclude particular domains within the organisation. This means that all representatives in the council must agree to any proposals brought forward, not just a simple majority. The idea behind this model is that, for the most part, experts within each circle are qualified to manage their own operations discretely and independently, with the broader organisation being relied upon to represent the organisation publicly and build the community. 
COPIM is designing a number of different independent elements that may benefit from a Circles model of governance. Currently, each work package is focused on a specific area - university press models, metadata infrastructure, funding model, etc - that will need governance for the long-term. Representatives from each work package could form a council to provide oversight of the future of COPIM while independently managing their own operations. This would allow representatives from each work package to agree on the values, principles and bylaws that govern the organisation, and then govern the future of COPIM accordingly. To add to the complexity, each circle would need its own form of governance, although this could be decided by the circle itself, rather than the project at large.

Yet the Circles model presents a problem for COPIM because it does not adequately account for external community members that may have a stake in the project but do not participate in the day-to-day running of it. For example, the consortial funding model will involve libraries contributing both financially and to the governance of the monograph publishing platform, although they will not be publishing any books themselves.

Similarly, COPIM hopes to be accountable to stakeholders such as early-career researchers and authors, though it is unclear whether they would deserve equal representation in the council, especially given the fact that unanimous consensus is required such that anyone could prevent an action from passing. Related to this is the concern about inequality of contribution leading to equality of representation. For example, the Circles model would lead to equal representation for libraries that contribute different amounts of money to the model. This may be desirable - and would certainly benefit less wealthy institutions - but it is also worth noting as a potential concern.

\section{Jury and Petition}

Two related models proposed by CommunityRule are governance by jury. and by petition. In the jury model, agreements are implemented through 'ad hoc juries made up of randomly selected members'. Anyone associated with the project can propose an issue for discussion and implementation by the jury. The project can decide whether a simple majority or unanimous consensus is needed for motions to be carried. Similarly, the petition model allows anyone to propose an issue to be debated and implemented, although motions are subject to referenda if a third of the membership agrees it should be voted on. If $2 / 3$ of the votes are in favour of the petition, it is carried. 
Both the petition and jury models seek community rule by assuming that anyone connected with the project can make decisions that affect it, though, of course, deciding who is sufficiently connected to the project is also itself a task of the governance model. As examples of representative and direct democracy, these models assume that all members are motivated, free, and knowledgeable enough to participate in decision making, subject to motions being given sufficient discussion and debate time. Yet for a multi-stakeholder organisation like COPIM, this might pose a problem because neither model would ensure adequate representation of all stakeholders and could grant too much power to one stakeholder group. This would require some way of deciding if certain working groups (which may be larger or more important to the project) deserve more representation. The jury model could then be tweaked to include a random member from each stakeholder grouping, rather than from the project more generally, although this would require all stakeholders to be equally versed in the activities of COPIM.

\section{Meta-governance}

For our purposes, two drawbacks of the governance models discussed in CommunityRule are the lack of concrete examples of how they are deployed in realworld settings, alongside a lack of consideration of broader stakeholder complexities that may govern an organisation. This means that the models remain quite simplistic and overly theoretical, rather than relating to situational concerns and common problems with implementing such models. However, it is not the purpose of CommunityRule to account for such complexity; they are only presenting templates for small community-led organisations to get inspiration from and so can only form a part of the larger governance model that COPIM requires. Nevertheless, some of these concerns are addressed in a broader project from the same group of authors called 'Metagovernance'.

Although the Metagovernance project is still nascent, it suggests ways in which smaller community projects might connect with others to integrate governance agreements between stakeholders. Similar to CommunityRule, these agreements take the form of rules between developers, platform operators, and users or other stakeholders (ig 4. .). The difference is that governance here is conceptualised not just within the project but between different projects too. So, for example, organisations such as university presses that interact with COPIM could do so on the basis of a series of agreements rather than formal participation as project members. This participation would be more than a mere contractual arrangement, because it would 
entail certain governance activities, but it would stop short of full project participation and responsibility.

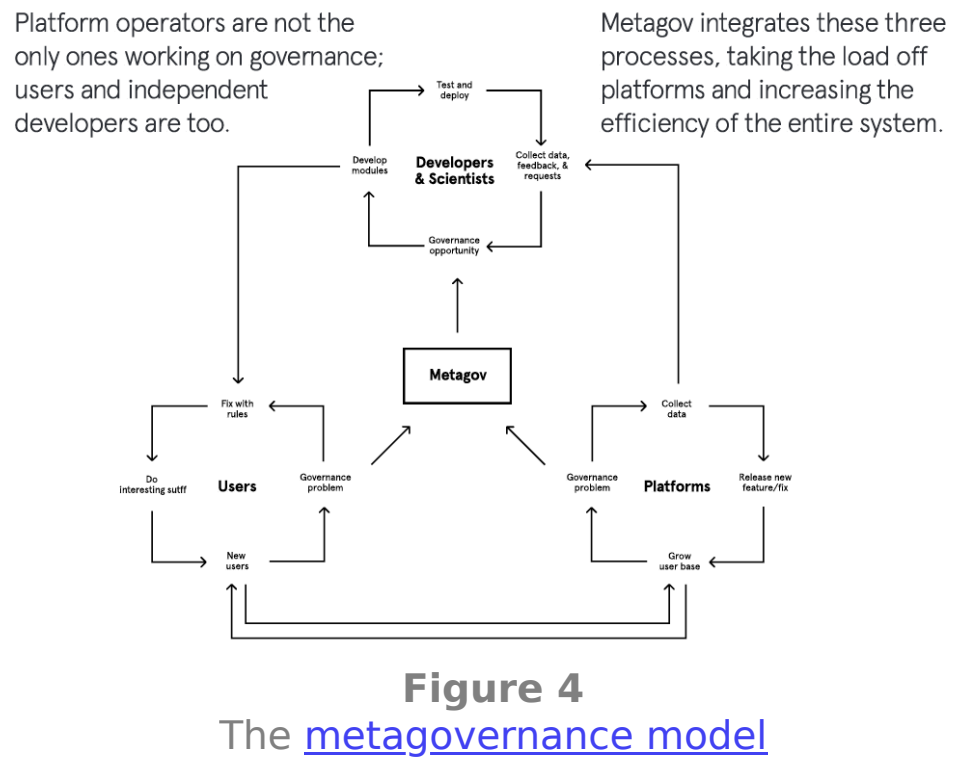

Using tools such as Loomio - an online platform for community management and consensus-building - metagovernance is a protocol for connecting community governance models together. So, for example, one community might use an advisory board system, while another might use a jury-based system, but projects can be governed by the two by devising agreements to dictate their work.

Again, metagovernance is somewhat abstract without concrete examples of how these agreements should take place, but the project is still useful for considering communityled work with numerous stakeholders, work packages or separate elements that each need their own governance models. For example, in designing a governance system for the consortial model, COPIM could add metagovernance layers to connect to other elements in the overall governance schema. This could help admit new participants into COPIM while ensuring they commit to the rules that have been prescribed in advance. It could also enable agreements between certain parts of the organisation without affecting other areas (between open source software maintainers, for example). Though these are helpful points for COPIM to consider, the theoretical nature of CommunityRule and metagovernance does limit its utility for the project without practical applications of the models. 


\section{Commons governance}

Rather than beginning from theoretical or abstract models for governance, an alternative approach found within commons literature starts from a successfully managed community project, seeks to understand why it is successful, and then generalises outwards to see what lessons may be learned for governance more generally. The work of the Nobel Prize-winning economist Elinor Ostrom is useful in this regard. Ostrom pioneered the study of common-pool resources, such as reservoirs, forests and fisheries, seeking to understand how communities may self-organise to maintain such shared 'rivalrous' resources. Rivalrous here means that it depletes with usage - e.g., if you allow anyone to catch all the fish they want, the fishery will rapidly deplete with overfishing - and so rules and norms are needed if the resource is to be

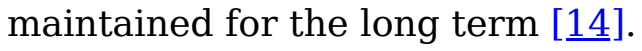

The COPIM project contains a mixture of non-rivalrous resources, such as digital publications and infrastructures that do not deplete with use, and rivalrous resources such as participant's time and consortial funding that is subjection to depletion. In addition, COPIM contains a mixture of excludable and non-excludable participants, e.g., readers cannot be excluded while certain publishers can. These features make COPIM a useful study in common-pool resource management. From studying such common-pool resources, Ostrom (1990,_p. 90). devised eight principles that are on display within the institutions that successfully manage common-pool resources (CPRs):

1. Clearly defined boundaries: both the resources being managed and shared and the communities that access and maintain them must be clearly defined.

2. Congruence between appropriation and provision rules and local conditions: Reiterating the need for situatedness, Ostrom argues that usage and participation rules should be set in accordance with local conditions, particularly those that relate to labour and material conditions.

3. Collective-choice arrangements: As far as is practical, individuals affected by the community rules can participate in modifying the community rules.

4. Monitoring: Monitors, who 'actively audit CPR conditions and appropriator behavior', are accountable to the community or participants in the community itself.

5. Graduated sanctions: Members who violate operational rules are likely to be assessed graduated sanctions ('depending on the seriousness and context of the offense') by other community members.

6. Conflict-resolution mechanisms: Community members should have access to lowcost dispute resolution mechanisms. 
7. Minimal recognition of rights to organize: The rights of community members to devise their own institutions are not challenged by external governmental authorities.

8. Nested enterprises: For larger common-pool resources, appropriation, provision, monitoring, enforcement, conflict resolution, and governance activities are organized in multiple layers of nested enterprises in which each nest has responsibility for its own area but is ultimately accountable to the larger community.

Note that these are features that Ostrom observed of good community management of shared resources, not a roadmap for how to arrive at good governance. Nonetheless, the principles are helpful to guide COPIM's approach to governance. In particular, principle 8 concerning 'nested enterprises' points towards the importance of polycentricity, or overlapping semi-autonomous areas within a common-pool resource that are 'nested' at different levels within the organisation [16]. For a complex community-governed organisation, polycentricity will be vital for avoiding simple hierarchies while still allowing for different areas of the organisation to control its own business. Ostrom (with her colleague Charlotte Hess) helpfully explains polycentricity in the context of institutional repositories:

In the example of building a university digital repository the levels of actions and decisions will be polycentric - that is, there will be decentralized, alternative areas of authority and rule and decision making. Say the intended action is to build a digital repository and populate it with faculty research products-both published and unpublished. There will be actions and decisions made by library committees and subcommittees and by the library administration. At the same time, there will be actions taken by faculty groups and committees, and multiple actions and decisions made by computer technology committees and groups [17].

Polycentricity responds to the fact that size and expertise matters in community governance. Smaller teams knitted together fare better than larger ones with single governance model; although ultimately, for Ostrom, the scale of the governance model should be tailored to fit the resource itself. Complexity should not be deployed for the sake of it. 


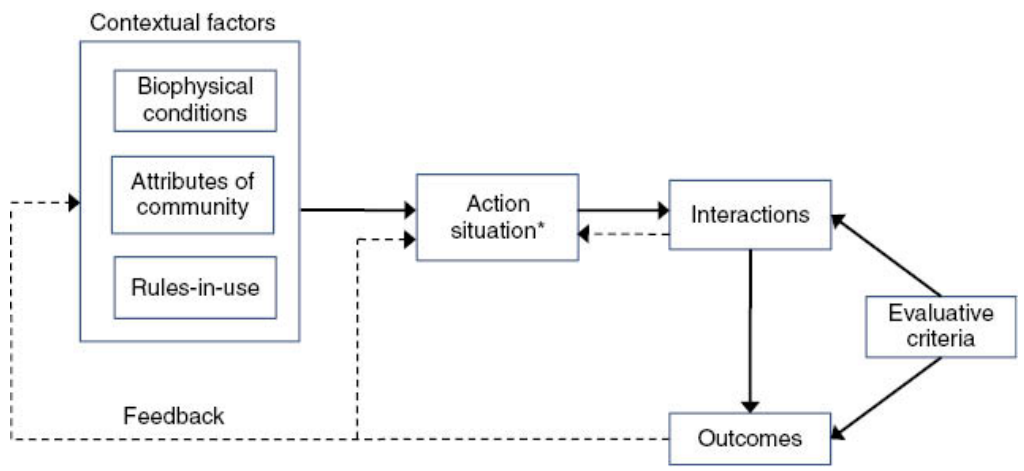

Figure 5

Basic components of the IAD Framework (Cole et al.). Reproduced under CC BY.

Ostrom also developed the Institutional Analysis and Development (IAD) framework to 'evaluate the effects of alternative institutional arrangements, and to investigate the processes by which institutions emerge and change over time' (ole et al.,2019). Figure 5 shows a simple version of this framework.

By plugging in different variables to describe the community and its work, it is possible to use this model to understand the kinds of governance structures needed. For example, for COPIM, the 'biophysical conditions' will refer to issues relating to digital monograph publishing, while 'attributes of the community' will refer to the stakeholders involved and their relative positioning within the organisation.

Developed in the 1980s, the IAD Framework has since been adapted to a range of different settings. For example, it has been updated by Frischmann et al. in the context of knowledge commons - shared community resources often based on digital information and infrastructures (2014,_pp. 24-26). Like Ostrom's work, the knowledge commons framework is designed to study commons rather than devise community governance models, but it is still helpful for exploring the attributes of successful commons. The authors list the following elements as necessary areas to explore when studying knowledge commons (2014,_pp. 24-26):

1. Resources - what is being shared and consumed, and by which actors?

2. Community - which actors make up the community and what are their roles?

3. Goals and objectives - what is the commons trying to achieve?

4. History and narrative - how did the commons come about, and where is it heading?

These considerations allow participants to decide the kinds of governance models employed within the knowledge commons. For example, the authors consider openness of community, openness of resources, and entitlement structures (who can access what 
and how) as vital in shaping governance. The governance mechanisms themselves include membership rules, contribution rules, resource extraction standards (how a resource can be used), conflict resolution methods, and sanctions for rule violation.

Although COPIM is currently in development, these questions will be answerable when we have a better idea of the financial and publishing models being developed and the infrastructures that will require governing for the long-term. This will allow for a robust and detailed description of the community that will lead to the forms of governance required. Once more, it is important to emphasise the situatedness that commons governance implies, and this situatedness can be crafted in terms of a rich narrative of the various actions, interactions, actors, and resources at play. This also means that governance is an activity community co-development, not just decided by one group at one time but continually evolving as the organisation itself evolves.

Examples of commons-based approaches are many and varied, foregrounding not just the formal structures that make up the commons but also the people who make up the commons (the commoners) and the practices of commoning that go into maintaining the resource through shared effort and mutual belonging [20]. The practices of commons may refer to small, informal projects such as church halls [21], roller derby clubs [22] and shared crafts workshops [23], and to larger institutions such as art schools [24] and multi-institutional collaborations that sequence genomes [25]. It is a situated mode of community governance that helps participants decide the rules, norms and structures for the project.

\section{Cooperativism}

One final mode of community-led governance worth considering is the cooperative. Though often described in terms of a commons, cooperatives emphasise community ownership over participation and so differ from commons approaches in that respect. In a cooperative, the people who use or run the organisation also own the organisation. This means that revenues and other resources are shared democratically, and the rules for participation are set by all owner-members. Though there are many different types of cooperative, COPIM might consider the benefits of giving members ownership of the organisation itself, rather than the right to simply govern it. According to the International Cooperative Alliance, there is an internationally accepted standard of values to which formalised cooperatives adhere. These values include:

1. Voluntary and open membership, such that all persons able to use their services and willing to accept responsibilities can participate in the cooperative 
2. Democratic member control in which all members have an equal vote;

3. Member economic participation in which revenues are shared between members;

4. Autonomy and control that is separate from private and state enterprise;

5. Education, training and information, whereby participation in the cooperative is not just for economic purposes but for developing new ways of working together cooperatively;

6. Cooperation with other cooperatives to strengthen the ecosystem

7. Concern for the community in which cooperatives give back to the communities in which they are embedded

These values map onto those of COPIM quite well, especially given the emphasis on democratic participation, cooperation with other like-minded initiatives, and care for the broader (open access publishing) ecosystem. A cooperative form of governance here would formalise participation within COPIM and ensure that it would be owned by its members in perpetuity.

Yet, as with the first section of this report, horizontality and equal participation becomes a problem with cooperativism. This is because of the size of the organisation and the diversity of stakeholders working within it, including the many and various libraries that will participate in the consortial funding scheme. Cooperativism is based on equal member participation and ownership that is perhaps more suited to smaller organisations than COPIM. For example, libraries will be providing funding for COPIM but it is not clear that they would have time to actively participate in the organisation as equal partners. Similarly, for publisher participants, how would COPIM equally share revenues when the contribution and return is unequal? These questions are not necessarily unanswerable, although they are challenging in complex, multi-layered organisations.

But the cooperative model does hold promise for COPIM as a kind of 'governance of governance' model. Similar to the idea of polycentricity discussed above, it would be possible for individual projects or work packages to manage their work according to their own hierarchical/informal governance structures and then govern the larger COPIM project according to a cooperative standard of one group holding one vote and receiving an equal share of resources for their own work. This would require coordination between groups but would ensure autonomy of the individual work packages that make up COPIM.

The Mondragon Corporation is a successful example of a Federation of Cooperatives that COPIM could base their model on. It is the largest and one of the most successful 
cooperatives in the world that houses 96 coops representing over 80,000 workers. Because of its size, Mondragon has numerous different governance structures within its organisation that are ultimately represented by a council, committee, president and vice president (Surroca et al.,_2006). Though this structure is somewhat corporate, it is cooperative in that all leadership positions are voted on by members, with one member receiving one vote. At the broader level, Mondragon operates a form of representative democracy through their board system, but on the individual project level, governance is more directly democratic. In cooperativism, therefore, the size of the organisation may have profound effects on governance structure.

\section{Conclusion}

This report has illustrated some of the different models that exist for community governance of multi-stakeholder projects, considering models in scholarly communication and more theoretical approaches to the commons and other forms of community accountability. In conducting this research, it has become clear that models for community governance are situated and that there are is no real 'off the shelf' approach that will work for complex organisations, not least because so much of governance refers to specific values, principles and norms dictating how participants interact with one another. Other considerations such as size, history, culture and the kind of resource(s) governed all play a factor in the sorts of accountability models that shape a project.

This means the task of designing governance for COPIM is not an easy one, especially as the resources being governed are still in development across the seven work packages. Yet this also points to the importance of process and co-development within governance: it will not be fixed in time but continually shaped by a range of actors in a number of ways. This is therefore a tentative conclusion to the report, which will grow into a larger document as COPIM figures out what it wants to be and as our values and principles become clearer and more consensual. The next stage of the process will be to create a narrative around the project, seeking to capture who COPIM is, what it is producing, what its goals are and where it is heading. In doing this, we will start to build a story around the project that will feed into the governance models being developed and help shape the direction of COPIM.

\section{References}

ACRL. (2006, September 1). Principles and Strategies for the Reform of Scholarly Communication. Association of College \& Research Libraries (ACRL). 
https://web.archive.org/web/20120207063448/http://www.ala.org/acrl/publications/whit epapers/principlesstrategies

Carlisle, K., \& Gruby, R. L. (2019). Polycentric Systems of Governance: A Theoretical Model for the Commons. Policy Studies Journal, 47(4), 927-952.

https://doi.org/10.1111/psj.12212

Cole, D. H., Epstein, G., \& McGinnis, M. D. (2019). The Utility of Combining the IAD and SES Frameworks. International Journal of the Commons, 13(1), 244.

https://doi.org/10.18352/ijuc.864

Contreras, J. L. (2014). Constructing the Genome Commons. In B. M. Frischmann, M. J. Madison, \& K. J. Strandburg (Eds.), Governing Knowledge Commons (pp. 99-136).

Oxford University Press. https://doi.org/10.1093/acprof:oso/9780199972036.003.0004

Crow, R. (2013). SUSTAINABILITY OF OPEN ACCESS SERVICES. SPARC and Knowledge Exchange. https://repository.jisc.ac.uk/6206/

De Angelis, M., \& Stavrides, S. (2010). On the Commons: A Public Interview with Massimo De Angelis and Stavros Stavrides. E-Flux, 17. http://www.eflux.com/journal/17/67351/on-the-commons-a-public-interview-with-massimo-de-angelisand-stavros-stavrides/

Dunbar-Hester, C. (2019). Hacking Diversity: The politics of inclusion in open technology cultures. Princeton University Press.

Fagundes, D. (2014). Labor and/as love: Exploring the commons of roller derby. In B. M. Frischmann, M. J. Madison, \& K. J. Strandburg (Eds.), Governing Knowledge Commons (pp. 417-444).

Oxford University Press.Fazackerley, A. (2021, January 29). 'Price gouging from Covid': Student ebooks costing up to 500\% more than in print. The Guardian. http://www.theguardian.com/education/2021/jan/29/price-gouging-from-covid-studentebooks-costing-up-to-500-more-than-in-print

Freeman, R. E. (1984). Strategic Management: A Stakeholder Approach. Pitman.Frischmann, B. M., Madison, M. J., \& Strandburg, K. J. (2014). Governing Knowledge Commons. In Governing Knowledge Commons. Oxford University Press.

Fyfe, A., Coate, K., Curry, S., Lawson, S., Moxham, N., \& Rostvik, C. M. (2017). Untangling academic publishing: A history of the relationship between commercial 
interests, academic prestige and the circulation of research.

https://doi.org/10.5281/zenodo.546100

Hess, C., \& Ostrom, E. (2007). Understanding knowledge as a commons: From theory to practice. MIT Press.

https://web.archive.org/save/https://www.wtf.tw/ref/hess_ostrom 2007.pdf

Houston-Knopff, R. \& Centre for Literacy of Quebec (Canada). (2009). Mutual

Accountability and Adult Literacy. Research Brief.

Moore, S. A. (2020, April 17). Without stronger academic governance, Covid-19 will concentrate the corporate control of academic publishing. Impact of Social Sciences. https://blogs.lse.ac.uk/impactofsocialsciences/2020/04/17/without-stronger-academicgovernance-covid-19-will-concentrate-the-corporate-control-of-academic-publishing/

Moore, S. A., \& Adema, J. (2020, April 27). Community Governance Explored. COPIM. https://doi.org/10.21428/785a6451.20a5c646

Olleros, F. X. (2018). Antirival goods, network effects and the sharing economy. First Monday, 23(2). https://doi.org/10.5210/fm.v23i2.8161

Ostrom, E. (1990). Governing the Commons: The Evolution of Institutions for Collective Action. Cambridge University Press.

https://web.archive.org/web/20210501221735/https://wtf.tw/ref/ostrom 1990.pdf

Parris, D., \& Williams, M. (2019). Care-full commoning at the Old Church on the Hill, Bendigo. Australian Geographer, 50(4), 531-546.

https://doi.org/10.1080/00049182.2019.1682289

Schneider, N. (2021). Admins, mods, and benevolent dictators for life: The implicit feudalism of online communities. New Media \& Society, 146144482098655. https://doi.org/10.1177/1461444820986553

Skinner, K., \& Lippincott, S. (2020). Assessment Checklist. Commonplace. https://doi.org/10.21428/6ffd8432.5175bab1/00710d8a

Skinner, K., \& Wipperman, S. (2020). Living Our Values and Principles: Exploring Assessment Strategies for the Scholarly Communication Field. Educopia Institute. https://educopia.org/living-our-values-and-principles/ 
Solfrank, C. (2019). Commoning the Institution - or How to Create an Alternative (Art School), When “There Is No Alternative.” On Curating, 43. https://www.oncurating.org/issue-43-reader/commoning-the-institution-or-how-to-create-analternative-art-school-when-there-is-no-alternative.html

Surroca, J., García-Cestona, M. A., \& Santamaria, L. (2006). Corporate Governance and the Mondragón Cooperatives. Management Research: Journal of the Iberoamerican Academy of Management, 4(2), 99-112. https://doi.org/10.2753/JMR1536-5433040202

Tkacz, N. (2014). Wikipedia and the politics of openness. University of Chicago Press. Udall, J. (2019). Mending the commons with the 'Little Mesters'. Ephemera: Theory \& Politics in Organization, 29. http://shura.shu.ac.uk/id/eprint/23989

\section{Footnotes}

1. Note: the author is a member of the OPERAS scientific advisory board $ヒ$

2. This will be done as part of a separate piece of research for COPIM which aims at producing official policies and procedures for the self-governance and administrative management of the infrastructures COPIM will create, $\subseteq$

\section{Citations}

1. Fyfe, A., Coate, K., Curry, S., Lawson, S., Moxham, N., \& Røstvik, C. M. (2017). Untangling Academic Publishing: A history of the relationship between commercial interests, academic prestige and the circulation of research. https://doi.org/10.5281/zenodo.546100

2. Moore, S. (2020). Without stronger academic governance, Covid-19 will concentrate the corporate control of academic publishing. Impact of Social Sciences. Retrieved from https://blogs.lse.ac.uk/impactofsocialsciences/2020/04/17/withoutstronger-academic-governance-covid-19-will-concentrate-the-corporate-control-ofacademic-publishing $L \boxminus$

3. Moore, S., \& Adema, J. (2020). Community Governance Explored. COPIM. Retrieved from https://copim.pubpub.org/pub/community-governance-explored 4. Houston-Knopff, R., \& Centre for Literacy of Quebec (Canada). (2009). Mutual Accountability and Adult Literacy. Research Brief. Retrieved from https://web.archive.org/web/20210502182902/http://en.copian.ca/library/research/co $\underline{\text { nnectdots/maal brief/maal brief.pdf }} \leftrightharpoons$ 
5. Freeman, R. E. (1984). Strategic management: a stakeholder approach. Boston: Pitman. $\subseteq$

6. Crow, R. (2013). SUSTAINABILITY OF OPEN ACCESS SERVICES: Phase 3: The Collective Provision of Open Access Resources. Retrieved from

https://repository.jisc.ac.uk/6206/

7. ACRL. (2003). Principles and Strategies for the Reform of Scholarly

Communication 1. Association of College and Research Libraries (ACRL). Retrieved from

https://web.archive.org/web/20120207063448/http://www.ala.org/acrl/publications/w hitepapers/principlesstrategies $\underline{\underline{\text { pes }}}$

8. Fazackerley, A. (2021). "Price gouging from Covid": student ebooks costing up to 500\%more than in print. The Guardian. Retrieved from

http://www.theguardian.com/education/2021/jan/29/price-gouging-from-covidstudent-ebooks-costing-up-to-500-more-than-in-print $\triangleq$

9. Skinner, K., \& Wipperman, S. (2020). Encouraging Adherence to Values and Principles in Scholarly Publishing: A case for assessment strategies. Educopia Institute. Retrieved from https://educopia.org/wpcontent/uploads/2020/03/NGLP PrinciplesValues WHITE-PAPER WEBFINAL-1.pdf $\triangleq$ 10. Skinner, K., \& Lippincott, S. (2020). Assessment Checklist. Commonplace. https://doi.org/10.21428/6ffd8432.5175bab1/00710d8a $\leftrightharpoons$ 11. Dunbar-Hester, C. (2019). Hacking Diversity: The Politics of Inclusion in Open Technology Cultures. Princeton, NJ: Princeton University Press. Retrieved from https://press.princeton.edu/books/ebook/9780691194172/hacking-diversity. 12. Tkacz, N. (2014). Wikipedia and the politics of openness. Chicago ; London: University of Chicago Press. Retrieved from https://press.uchicago.edu/ucp/books/book/chicago/W/bo19085555.html 13. Schneider, N. (2021). Admins, mods, and benevolent dictators for life: The implicit feudalism of online communities. New Media \&Society. https://doi.org/10.1177/1461444820986553 14. Olleros, F. X. (2018). Antirival goods, network effects and the sharing economy. First Monday. https://doi.org/1583677425 
15. Ostrom, E. (1990). Governing the commons: the evolution of institutions for collective action. Cambridge ; New York: Cambridge University Press. Retrieved from https://web.archive.org/web/20210501221735/https://wtf.tw/ref/ostrom_1990.pdf $\leftrightharpoons$ 16. Carlisle, K., \& Gruby, R. L. (2019). Polycentric Systems of Governance: A Theoretical Model for the Commons. Policy Studies Journal, 47(4), 927-952. https://doi.org/10.1111/psj.12212 17. Hess, C., \& Ostrom, E. (Eds.). (2007). Understanding knowledge as a commons: from theory to practice. Cambridge, Mass: MIT Press. Retrieved from https://web.archive.org/save/https://www.wtf.tw/ref/hess_ostrom 2007.pdf 18. Cole, D., Epstein, G., \& McGinnis, M. (2019). The Utility of Combining the IAD and SES Frameworks. International Journal of the Commons, 13(1), 244-275. https://doi.org/10.18352/ijc.864 19. Frischmann, B. M., Madison, M. J., \& Strandburg, K. J. (Eds.). (2014). Governing Knowledge Commons. Oxford University Press. https://doi.org/10.1093/acprof:oso/9780199972036.001.0001 20. De Angelis, M., \& Stavrides, S. (2010). On the Commons: A Public Interview with Massimo De Angelis and Stavros Stavrides. E-Flux, (17). Retrieved from https://www.e-flux.com/journal/17/67351/on-the-commons-a-public-interview-withmassimo-de-angelis-and-stavros-stavrides/ $\subseteq$ 21. Parris, D., \& Williams, M. (2019). Care-full commoning at the Old Church on the Hill, Bendigo. Australian Geographer, 50(4), 531-546. https://doi.org/10.1080/00049182.2019.1682289 22. Fagundes, D. (2014). Labor and/as Love: In B. M. Frischmann, M. J. Madison, \& K. J. Strandburg (Eds.), Governing Knowledge Commons (pp. 417-444). Oxford University Press. https://doi.org/10.1093/acprof:oso/9780199972036.003.0014 23. Udall, J. (2019). Mending the commons with the 'Little Mesters.' Ephemera: Theory and Politics in Organization, 19(2). Retrieved from http://shura.shu.ac.uk/23989/ 24. Sollfrank, C. (2019). Commoning the Institution - or How to Create an Alternative (Art School), When "There Is No Alternative." ONCURATING, (43), 5053. Retrieved from https://www.on-curating.org/issue-43-reader/commoning-the- 
institution-or-how-to-create-an-alternative-art-school-when-there-is-noalternative.html

25. Contreras, J. L. (2014). Constructing the Genome Commons. In B. M. Frischmann, M. J. Madison, \& K. J. Strandburg (Eds.), Governing Knowledge Commons (pp. 99-136). Oxford University Press. https://doi.org/10.1093/acprof:oso/9780199972036.003.0004

26. Surroca, J., García-Cestona, M. A., \& Santamaria, L. (2006). Corporate Governance and the Mondragón Cooperatives. Management Research: Journal of the Iberoamerican Academy of Management, 4(2), 99-112. https://doi.org/10.2753/JMR1536-5433040202 